\title{
RELIGION IN EDUCATION: AN EMOTIVE RESEARCH DOMAIN
}

Cornelia Roux

Petro du Preez

Stellenbosch University

South Africa

\begin{abstract}
Understanding religion and especially different aspects of world religions is today, more than ever, an important part of social science. Religion is not only a means whereby many different cultures categorise and define human values, but it also provides a way in which to understand diversity in humankind's experiences with life as part of our quest for meaning. Religion, as a component of the curriculum in education, be it in a home school environment, in schools or at tertiary institutions, is also a vibrant and important research domain. In the quest for greater understanding of people's perceptions, attitudes, feelings and experiences, as well as their own religions and those of others, empirical research seems to be an effective route to follow. In this article the authors theorise on different research designs and methodologies to be applied in religion in education as a research domain and argue for a cautious approach to and analyses of empirical data. This article contains many claims made by the authors based on their experiences of research on Religion in Education.
\end{abstract}

Key Concepts: Research domain, theoretical notions, empirical methodologies, emotive responses

\section{Introduction}

Religion in education (RiE) is a social scientific research area. Mouton (1996:17) elaborates on four images of scientific inquiry: Research as the search for truth (the epistemic model); research as a problem solving social activity (sociological model); research as the production of knowledge (economic model) and research as project management (the management model). Research in RiE can thus be regarded as a problem solving social activity and a collaborative social activity and a social practice (sociological model) (Mouton, 1996:41). Research in RiE, however, can also occur as the production of knowledge, and therefore fit into the economic model. In studying research in $\mathrm{RiE}$ the epistemic and management model might also become evident. However, for the purpose of this article these frameworks will not be explored.

This means that researchers in RiE form a scientific community and reflect in their research on what they value as the social dimensions of religiosity. It is also a fruitful opportunity for collaboration between researchers and educators in religion.

$\mathrm{RiE}$ has been a rigorous field of study for at least the past four decades. The recognition of the diversity of cultures and religions in society at large influenced the traditional religious approaches in education (Smart, 1971; 1989). Towards the latter part of the twentieth century, the change from a monoreligious to a multireligious approach towards 
RiE became a reality in many countries. The debates started mainly with the influences and results of development projects and publications of Ninian Smart (1971; 1989). His contributions towards teaching learners to understand the fact of diversity in religions influenced many scholars in religion education. This led to several changes in various education policies and school curricula. The tension or various kinds of compromises between these two above-mentioned approaches had a direct influence on the role of RiE. This highlighted the necessity for empirical research in Religion Education. ${ }^{1}$ Educationalists in the field of Religion Education began to analyse the importance of religions taught in a secular environment and their influence on various aspects of learners' development.

The contributions of $\mathrm{RiE}$ to intercultural education, however, were and are still not always appreciated by religious communities at large. Media reports, societies' perceptions and educators' influence on students and learners frequently provoke questions and raise thorny issues concerning the notion of teaching and/or facilitating different religions. Religious Education, as a subject in schools, and as a concept, has different meanings for different educational environments. In many European countries Religious Education comprises multireligious contents in school curricula. In South African schools, in the previous education dispensation, Religious Education was known as Bible Education, Religious Instruction or Right Living (Summers \& Waddington, 1996), and entailed a monoreligious (one-religion) approach and curriculum. The new Policy on Religion and Education (2003) describes the multireligious approach in South African schools as Religion Education. The authors of this article argue that the concept religion in education should be used to define a broader notion than religious education or religion education. ${ }^{2}$ Religion in education (RiE) involves, amongst others, developing philosophical ideas and theories on religion and education; carrying out empirical studies and research involving educators, students and learners; developing curricula; and exploring innovative methodologies for the teaching and learning of religion in education.

The aim of the article is to:

- underpin theoretical notions on empirical research in RiE;

- address the needs for empirical research;

- elaborate on the research processes and methodologies and

- to define the role of the researcher and participant in RiE.

\section{Need for Empirical Research in Religion in Education}

It seems that the two main fields of empirical investigation researchers tend to explore are attitudes to and/or perceptions of religion and $\mathrm{RiE}$. Undertaking empirical research in $\mathrm{RiE}$, especially with teachers and learners in schools and students at tertiary level, is not an easy task. The underpinned attitudes and perceptions that exist, the influences of religiosity, ${ }^{3}$

\footnotetext{
Religion Education is a non-confessional approach of studying different religions and where learners can also reflect on their own beliefs and values (cf. Roux, 1998; Roux and Steenkamp, 1995; 1997).

2 For a full and interesting discussion on the relationship between Religious Education, Religious Studies and Theology see Cush, 1999, in British Journal for Religious Education.

3 Religiosity manifests itself in the way a person conducts a religion and/or belief system in a personal, religious, spiritual, economic, political and social construct of society and different world-views.
} 
people's cultural and social environment, their personal religiousness ${ }^{4}$ and spirituality are some indicators that can determine the so-called successes or failures of research and in some instances even question the validity of data. It is therefore important to argue that theoretical notions and explorations support empirical research and that philosophical theories on $\mathrm{RiE}$ provide a foundation and point of departure for understanding the broader spectrum in RiE.

In a changing society, both locally and globally, it appears that in the area of RiE the media, general public, parents and politicians define the needs pertaining to learners' religiousness, attitudes to and perceptions of religion. It seems also that personal feelings or sweeping statements reported in the media on different aspects regarding RiE sometimes undermine the acceptance of research data. One can argue that research data on abovementioned matters is often viewed with suspicion and repeatedly questioned. It seems that these perceptions and attitudes will have to change in order to create a healthy environment for research in RiE. Two questions in this regard should then be asked: Firstly, why do people who are not experts in this field of study, act in such an emotive way, and secondly: What is the value of research in addressing emotive responses to research in RiE?

In an attempt to provide answers for the abovementioned questions, it is necessary to give some indications as to how research in $\mathrm{RiE}$ can contribute to this emotive field of study. Various reasons can be given: Firstly, it can assist in clarifying the issue of the diversity of perceptions, attitudes and beliefs of participants, be it teachers, learners and parents, or social issues directly or indirectly involved with RiE. This type of research can also contribute to the understanding and clarification of one's own religion, since it gives one the time to reflect on what one usually will not criticise. ${ }^{5}$ Secondly, it can contribute to the process of selecting the best pedagogical strategies for facilitating RiE. It plays an important role in the alleviation of identified problems and challenges in the discipline. It also helps the various role-players to understand the relevant social phenomena and to determine the impact of certain interventions in the field of study. Research can also contribute to the establishment of interaction between different disciplines in social sciences and education. Finally, an understanding of the experiences and emotions of participants during research projects will create the opportunity to explore further the emotive underpinning of research in RiE. It seems that empirical research per se provides a perspective and a foundation for exploring and defining emotive responses.

Empirical research projects in RiE appear to be more appropriate when supported by ethnographic designs. Mouton (2001:148) describes ethnographic research as ... studies that are usually qualitative in nature, which aim to promote an in-depth description of a group of people or community. Especially in $\mathrm{RiE}$ in-depth issues can only be explored when all variables of the community are taken into consideration. Mouton (Ibid) states further that (s)uch descriptions are imbedded in the life-worlds of the actors being studied and produce insider-perspectives of the actors and their practices. Nesbitt defines the concept ethnography in her research in $\mathrm{RiE}$ as an approach to understanding others which relies on a discipline of deep listening and close reflective observation (Nesbitt, 2004:5).

4 Religiousness is a conscience dependency on a deity/God and the transcendent. It is more evident in one's commitment, one's personality, experiences, beliefs and thinking in devotional practice, morality and other social activities. See Tamminen, 1991.

5 See forthcoming publication; P du Preez and C Roux, Clarifying students' perceptions on different belief systems and values: Prerequisite for effective educational praxis. 


\section{Three Worlds in Research in RiE}

Research in RiE varies from entirely qualitative, ethnographic research (empirical studies) (Nesbitt, 2004; Ferguson and Roux, 2004) to more philosophical, conceptual studies (nonempirical studies) (Jackson, 1997). These different methodologies used in social research have multiple purposes. Babbie (1979:110) states that there are three major purposes of research, namely exploration, description and explanation. Research also serves as a way to inform the general public, scholars in a specific field of study, and decision-makers in various fields such as policymakers, curriculum designers, etc. According to Taylor (2000:172) research is mainly theoretical, empirical or applied. She argues, from her research done in value education, for a more theoretical and philosophical approach in order to elucidate and clarify concepts and issues and to indicate ways forward. The theoretical and philosophical approach must, however, not be the only means to research in RiE. Empirical research is just as useful, if it is done vigilantly while being grounded in theoretical notions. Therefore empirical research in RiE should take cognisance of theories and methodologies in education research. The application of empirical and theoretical notions will strengthen and enhance the quality of research and elucidate another means to the triangulation of the data.

Mouton's (2001) description of research as a means to produce knowledge is also relevant. It can be argued that research, as a means of producing knowledge, has the potential to eliminate the notion that everything in $\mathrm{RiE}$ can be viewed as common knowledge. Mouton argues that knowledge can be grouped into three different worlds (1996:7-10). The first world can be described as everyday knowledge, i.e. lay knowledge that will enable us to cope effectively with our daily tasks. One can argue that common knowledge originates from this type of knowledge. He contrasts the world of lay knowledge with the two worlds especially relevant to researchers, namely the world of science (scientific knowledge) and the world of meta-science (meta-scientific knowledge). The distinctive feature of the world of science, according to Mouton (1996:8), is that scientists typically make phenomena of the world of lay knowledge (the world of politics, economics, religion, the animal/plant world, etc.) into objects of inquiry. Therefore, in the world of science, researchers in $\mathrm{RiE}$ can change that which is viewed as common knowledge into objects of research in order to clarify that which is viewed as lay knowledge. Mouton further argues that in the world of meta-science (literally going beyond or transcending science, or reflecting on science), human beings have a self-conscious and continuous reflecting nature. Research within the former context thus provides opportunities to continually re-evaluate what is viewed as knowledge within RiE. In this way both laity and scholars can be informed, and at the same time reflective research can be done in religion education in order to improve classroom practice in schools and in tertiary institutions. It is therefore appropriate that research in $\mathrm{RiE}$ should encounter all three worlds to ensure that all three worlds of knowledge are covered and developed and to improve on the effectiveness and validity of the research.

\section{Research Designs and Methodologies in Religion in Education}

Research in RiE often describes only certain attitudes, trends or issues. In order to ensure accountability in this research domain, it is important for the researcher to formulate a welldefined research design when devising a framework for the research. This includes certain predetermined epistemological and ontological assumptions that will shape and determine the methodologies to be used. 
Descriptive research is important to set the scene for inquiries and to inform both laity and the scientific community on various aspects of RiE. However, it does not appear to be sufficient. It is therefore necessary to embark on studies that ask questions about attitudes, trends and issues that can assist the scientific community in understanding the complex phenomena such as perceptions. Wellington (2000:49) maintains that the type of questions to be asked before conducting one's research, determines the nature of research to be embarked upon. He states that what, which and where questions involve descriptive research that is usually quite up-front, stating the problem and receiving data to support the statement. On the other hand, why and how questions in RiE, that are exploratory and explanatory in nature, are complex, intractable and more interesting than the former. Theoretical notions need to be comprehended before embarking on gathering empirical data. These issues seem to be key factors when considering research questions in RiE. It will not only influence the research design and methodology (i.e. qualitative or quantitative methods), but will eventually answer the proposed research question and influence the analyses of the selected data.

The choice between quantitative or qualitative methodologies ${ }^{6}$ determines the methods of sampling, data collection and analyses of the research. Due to the vast differences between the epistemological, ontological and methodological assumptions underlying these designs an understanding of possible research outcomes should be clarified.

The predominant use of quantitative methodologies in RiE should be questioned. The reason is that this method seems not to explore all the variables imbedded in perceptions underlying certain attitudes in religion and belief systems. In a quantitative framework research is described as objective, value-free and neutral, one in which the social world is described as if it is the natural world (Wellington, 2000:18). Such an approach to research might eliminate the inclusion of subjective notions that underlie studies in RiE. These subjective notions include participants' and researchers' own socio-cultural backgrounds, religiosity, religiousness and spirituality. Using technology, for example only e-mails, as means to collect attitudinal data and deriving at certain assumptions regarding perceptions, specifically on religious issues, such a method seems to be improper. Quantitative methods might only be valuable if complemented by a well-defined qualitative methodology.

The qualitative research methodology, however, seems to provide a departure point for the inclusion of abovementioned subjective notions. McKie (2002:264) reinforces this notion when she states that qualitative research can provide important insights into different perceptions of reality. Qualitative research also involves an encounter with the world and the ways in which people construct, interpret and give meaning to their experiences (Gerson and Horowitz, 2002:199). This selected design, methodology or method allows the researchers and participants to walk the path ${ }^{7}$ together. The process of engagement by the researchers proved to be vital for understanding the complexity underlying the exploration of individuals' and/or groups' perceptions in $\mathrm{RiE}$ as a research domain. ${ }^{8}$

$6 \quad$ While methods refer to the techniques and procedures used to gather data to be used for inference and interpretation, methodologies have the purpose of describing and analysing methods to clarify their presuppositions, limitations and consequences (Cohen and Manion, 1994:38-39).

7 Walk the path is defined by the authors as the process of engagement and reflects a form of pastoral care (empathy) between the researcher and the respondent/participant during the research, as well as during the analyses of the data, especially in $\mathrm{RiE}$.

8 See forthcoming publication: $\mathrm{P}$ du Preez and C Roux, Clarifying students' perceptions of different belief systems and values: Prerequisite for effective educational praxis. 
Attitudes, trends and issues in RiE often manifest as undefined emotive responses. It is necessary to embark on studies that search for the underlying perceptions or notions of these attitudes, trends and issues. If such perceptions and notions underlying emotional responses become defined, clarified or merely explored in collaboration with the participant, it might lead to altered perceptions. Participating action research has the propensity to bring more relevant issues regarding the participants' perceptions towards research in $\mathrm{RiE}$ to the fore. Participatory action research, especially in $\mathrm{RiE}$, attempts to make the different kinds of decisions more consciously and can therefore be viewed as one way to commence a transformation process regarding perceptions of religious and/or spiritual issues. Mouton (2001:150) states that the commitment with this empirical research methodology is to empower the participants and to define the changing of the social conditions of the participants. The qualitative methodology forms an integral part of the research and therefore the researcher and the participant are involved in personal reflections (religiously or emotionally) on either the perceptions or the given data. This empowerment agenda might have the propensity to lead to altering an individual's perceptions.

Researchers in RiE engage in different aspects of the social world of participants. Observational studies as method may assist researchers in this area to view participants' social actions in different dimensions and therefore observe the significance of actions. Ehrich (2003:56) argues that observation compels the researcher to observe the actions both as a participant and as an observer. These observations should enable the researcher to authentically understand the life-worlds of the participants s/he encounters. It can be argued that in order to contribute to the change of participants' attitudes or perceptions, the researcher's participation should cover a relatively long period. This involvement also establishes the notion of walking the path with participants as argued before.

The in-depth interview is a method whereby a researcher can become familiar with participants and their life-worlds. This research method is well established in research on RiE (Roux, 1998; Roux and Ferguson, 1999; 2003; 2004). Gerson and Horowitz (2002:204) claim that effective interviews need to guide respondents through a maze of life experiences in an orderly fashion. According to these authors this method of interviewing involves questions on the actual event and the social context in which the event or experience occurred. This process engages the person's behavioural response, feelings, perceptions and beliefs before, during and after the particular experience (Gerson and Horowitz, 2002:206). In-depth interviews in conjunction with participating action research and/or observational studies may significantly contribute towards fully comprehending a situation as well as towards suggesting and contributing to positive change in those involved. Interviews provide the opportunity for researchers and participants to engage in dialogues to clarify different aspects or situations that have been observed.

\section{The Position of the Researcher towards the Participant}

The researcher's stance of involvement in, and the process when determining the lifeworlds of participants in $\mathrm{RiE}$, need to be both reflexive and reflective (Wellington, 2000:42). The former involves reflecting on oneself and is also a subset of the latter. Being reflective involves thinking critically about the research process (ibid). This process does not only form part of the social world being scrutinised, but it might also lead to outputs being more truthful. Research in $\mathrm{RiE}$ acquires a responsibility from researchers that becomes evident especially during the engagement between the researcher and participant(s). The researcher has the responsibility to understand and know the participants life-worlds, especially in ethnographic research (Wellington, 2000:44). The researcher in RiE should be 
well-informed about matters such as the participant's language, religion, belief system, economical and cultural background as well as intrinsic knowledge ${ }^{9}$ in order to contextually understand his/her actions and responses. Contextualisation in RiE is imperative in order to comprehend the intricacy of the participants' life worlds. Ethnographic research in RiE can be challenging and questionable if the role of the researcher as an insider or outsider or insider/outsider ${ }^{10}$ is not explicitly stated and defined (McCutheon, 1999; Roux, 2001). The position of the researcher could influence the outcome of the analyses of the research data or proposed guidelines. Another factor is that the outcomes may also have been influenced by the participants' intrinsic knowledge, fears, emotions and/or positive or negative perceptions of religions and belief systems other than their own. Therefore the predetermined position of the participant as an insider or outsider or insider/outsider during interviews on different religions or belief systems should also be mentioned. Experiences in empirical studies in RiE will enhance the researcher's ability to identify his/her own position in this regard. The reason is mainly to minimise a subjective approach to the research in question.

An interesting statement by Nesbitt (1999:82) is that the research process in religion may contribute to the researcher's spiritual journey. It is therefore possible to argue that research projects might also influence researchers' and participants' own religiousness. It therefore seems essential that respondents or participants identify their own religiousness and religiosity before participating in the research.

\section{Ethics}

Ethics is a vital aspect when engaging in research in RiE. Research in RiE has the propensity to evoke different emotions from the participants. Researchers should therefore react sensitively and respectfully to the participants' emotions within an ethical frame of reference. Ethics should not only be part of the actual process when collecting data, but should also form an integral part of the research design, the methods to be employed, the analyses of the data and the presentation thereof (Wellington, 2000:55-56). The researcher should adhere to these issues and informatively explain and communicate to the participants their ethical rights. Authors of academic articles should, on the other hand, also be cautious not to disseminate and present their empirical data and responses of respondents in an emotive writing style.

\section{Target Groups}

Target groups in this research domain (RiE) are predominantly educators, students and learners. Educators in religion education, especially in the school system, often regard their teaching profession as a calling. In this sense, a confessional approach ${ }^{11}$ especially in the Abrahamic religions, may occur. This approach manifests mainly within Christian denominations. ${ }^{12}$ This professional attitude and approach was clearly identifiable in research

9 Intrinsic knowledge refers to any kind of knowledge owned by an individual before he or she formally embarks on an intensive study on a specific topic. This type of knowledge can consist of ego-identifications (Paul, 1984) - that knowledge we take uncritically from our parents and other influential people during our forming years - in addition to that which we may consider to be common knowledge.

10 Insider/outsider is defined as a person/researcher/participant of the same religion or belief system, but who does not adhere to the same denomination or grouping.

11 A confessional approach means that a teacher may introduce her/his own religion to learners as the only religion to adhere to.

12 Before 1994 the then Christian National Education system allowed teachers to use the confessional approach. However, many teachers still used this approach before the new policy was introduced. The Policy on 
projects with teachers (Ferguson and Roux, 2003; 2004) and pre-service teachers (students). ${ }^{13}$ Researchers should, however, be sensitive when dealing with learners (participants) within the school context, in view of the possible impact of research on their religious and emotional development. As stated above, this aspect requires a clear identifycation of the insider/outsider position with the intention of being more objective towards the required research data and the analyses thereof. The emotive responses intertwined with personal belief and religious convictions during the feedback (different responses) urge the researcher to walk the path with her/his participants, during the collection of the data. Research has shown (Roux, 1998; Ferguson and Roux, 2003; 2004) that the responses of participants can be emotionally and conceptually loaded and might therefore become very difficult to analyse. Therefore it can be argued that the use of multiple methods might improve the quality of research and the analyses of the responses (Mouton, 1996), in order to overcome emotiveness.

\section{Conclusion}

In this article the authors elucidated the contribution that specific research methods in RiE can make to deal with participants' emotive responses. It was argued that outcomes and processes in research in $\mathrm{RiE}$ often seem to evoke emotive responses based on participants' religiosity, religiousness, attitudes and perceptions. Research processes are often distorted as a result of various influences such as participants' own religious obligations, beliefs or value systems. One should take note that the selection of apt research designs, methodologies and methods also plays an important role in the manner in which transformation in participants' perceptions and attitudes will transpire. Descriptive research processes are therefore not enough to initiate transformation in this regard. Exploratory and explanatory research has the propensity to facilitate transformation due to the fact that there is a deeper search for meaning since it does not only describe issues, trends and attitudes. The authors reflect on the different aspects that the researcher in $\mathrm{RiE}$ should embark upon and cautiously take the responsibility of pastoral care and the important position with regard to the position of being an insider, outsider or insider/outsider. Research in RiE can be considered a challenging and exciting domain because of the deliberate contribution towards understanding the religious phenomena in all their different spheres.

Religion and Education was only introduced by the National Department of Education (DoE) in September 2003.

13 See forthcoming publication: P du Preez and C Roux, Clarifying Students' perceptions of different belief systems and values: Prerequisite for effective educational praxis. 


\section{BIBLIOGRAPHY}

Babbie, ER 1979. The Practice of Social Research. $2^{\text {nd }}$ ed. Belmont/California: Wadsworth Publicising Company Inc.

Cush, D 1999. The relationship between Religious Studies, Religious Education and Theology: Big Brother, Little Sister and the Clerical Uncle? British Journal of Religious Education. 21(3):137-146.

Ehrich, LC 2003. Phenomenology: The quest for meaning. Qualitative Educational Research in Action: Doing and Reflecting, eds. O'Donoghue, T \& Punch, K. London/New York: RoutledgeFalmer. 42-69.

Ferguson, R and Roux, CD 2003. Teacher participation in facilitating beliefs and values in Life Orientation programmes. South African Journal for Education. 23(4)273-275).

-- 2004. Teaching and learning about religions in schools: Responses from a participation action research project. Journal for the Study of Religion. 17(2)5-23.

Gerson, K and Horowitz, R 2002. Observation and Interviewing: Options and Choices in Qualitative Research. Qualitative Research in Action, ed. May, T. London/Thousand Oaks/New Delhi: Sage Publications. 199-224.

Jackson, R 1997. Religious Education: an interpretive approach. London: Hodder and Stoughton.

Kung, H 1995. A Global Ethnic and Education, The British Journal of Religious Education. 18(1)6-21.

McCutheon, RT 1999. The Insider/Outsider Problem in the Study of Religion. London: Cassell.

McKie, L 2002. Engagement and Evaluation in Qualitative Inquiry. Qualitative Research in Action, eds. May, T. London/Thousand Oaks/New Delhi: Sage Publications. 261-285.

Mouton, J 1996. Understanding Social Research. Pretoria: Van Schaik Publishers.

Mouton, J 2001. How to succeed in your Master's and Doctoral Studies: A South African guide and resource book. Pretoria: Van Schaik Publishers.

Nesbitt, E 2004. Intercultural Education: Ethnographic and Religious Approaches. Brighton/Portland: Sussex Academic Press.

Paul, RW 1984. Critical Thinking: Fundamental to Education for a Free Society. Educational Leadership. 42(1):4-14.

Roux, CD and Steenkamp, D 1995. A Curriculum Proposal for the School Subject Religious Studies. Scriptura: International Journal for Bible, Religion and Theology in Southern Africa. 53(2)73-95.

-- $\quad$ 1997. The Christian teacher and multireligious education. Pretoria: Via Africa \& Nassau Publishers.

Roux, CD 1998. The need for a paradigm shift in teaching religion in multicultural schools in South Africa. South African Journal of Education. 18(2), 84-89.

-- 1999. Facilitating religion in Life Orientation programmes: Challenges for a developing multicultural society. Journal for the Study of Religion. 12(1 \& 2):113-122. 
-- 2001. Religion in Education in South Africa: Myth or reality? Panorama (International Journal of Comparative Religious Education and Values). 13(1):17-26.

Smart, N 1971. The Religious Experience of Mankind. Glasgow: Collins.

-- 1989. Should pupils be educated religiously in a pluralistic world? The HongKong Journal of Religious Education. 1:42.

Summers, HC and Waddington, RR 1996. Religious Education for transformation. Pretoria: Kagiso Trust.

Tamminen, K 1991. Religious Development in Childhood and Youth. Helsinki: Suomalainen Tiedeakatemia.

Taylor, M 2000. How can Research into Education in Values help School Practice? Values and the curriculum, eds. Cairns, J; Gardner, R \& Lawton, D. London: Woburn Press. 167-186.

Wellington, J 2000. Educational Research: Contemporary Issues and Practical Approaches. London/New York: Continuum.

\section{Reports}

2003 National Policy on Religion and Education. Department of Education, Pretoria: Government Printers. 